\title{
Classification of Thermal Images of Bovine Mastitis by Computer Vision
}

\author{
Rodes Angelo B. da Silva \\ Doctoral Student \\ Department of Agricultural \\ Engineering \\ UFRPE
Recife, PE
Gledson Luiz P. de Almeida
Professor of the agricultural
engineering department
UFRPE/Recife, PE

\author{
Borko Stosic \\ Professor at the Department of \\ Statistics and Informatics (DEINFO) \\ UFRPE \\ Recife, PE
}

\author{
Marcos Vinícius da Silva \\ Doctoral Student \\ Department of Agricultural \\ Engineering \\ UFRPE/Recife, PE
}

\author{
Héliton Pandorfi \\ Professor of the Agricultural \\ Engineering Department \\ UFRPE \\ Recife, PE
}

\begin{abstract}
This study was conducted with the objective of developing a software program, based on image processing and computer vision techniques, as a tool to aid in the monitoring and early detection of clinical manifestations of bovine mastitis. Twenty-four lactating Girolando cows and distinct clinical conditions (healthy, subclinical mastitis and clinical mastitis) were selected. Thermal images of the udder surface of the animals were taken using an infrared thermal imager from the left anterolateral, right anterolateral, posterior and inferior views, four images per animal, totaling 96 thermal images. The images were preprocessed by thresholding, implementing the Hoshen-Kopelman algorithm, to organize the data through the size of the clusters, labeled between 34 and $38{ }^{\circ} \mathrm{C}$. The developed software program proved to be efficient in classifying thermal images for detecting the clinical pictures of mastitis, with accuracy of $90.9 \%$, specificity of $57.14 \%$ and sensitivity of $85.71 \%$; however, it was observed that the angles at which the images were recorded may influence the classification result.
\end{abstract}

\section{Keywords}

dairy cattle, computer program, animal health, infrared thermography

\section{INTRODUCTION}

Brazil occupies the fifth position among the world's largest producers of milk, with a $31.67 \%$ increase in its production between 2006 and 2017][9]. Despite the socioeconomic relevance of the activity, numerous problems have reduced the productive efficiency of the national herd, making it difficult to achieve the indices of profitability and at the same time protect human health, animal health and the environment. These problems include particularly the incidence of mastitis, responsible for production losses, which can make the exploitation of the activity unfeasible, causing economic losses, depreciating the quality of the final product, increasing costs with treatments and, in some cases, generating problems of public health [10]

Clinical mastitis is diagnosed by the most pronounced inflammatory condition, such as edema, increased temperature, hardening and pain in the mammary gland, appearance of lumps, pus or alterations in milk characteristics. For its detection, a thorough examination of the mammary gland and the black-bottomed mug test are performed. In the subclinical phase, there are no visible changes in the aspects of milk or udder, but rather an asymptomatic infection, which results in alteration of milk composition, generally detected by the California Mastitis Test [16]

In this context, infrared thermography (IRT) has assisted in the diagnosis of infectious conditions that cause alterations in body surface temperature, in the area affected by the disease. Among some studies of zootechnical interest, [6] and [13] stand out. These authors studied infrared thermography as a diagnostic tool for detecting subclinical mastitis and found differences between temperatures of healthy udder and udder with mastitis. [12] studied the variation of inflammatory dynamics after experimentally induced Escherichia coli mastitis using thermography and verified its efficiency in detecting temperature changes of 2 to $3{ }^{\circ} \mathrm{C}$ on udder skin surface. [7] and [15] studied IRT as a method of disease prevention, identifying temperature elevation before the onset of the first clinical signs.

Concomitantly to obtaining the thermal image, computer vision helps its interpretation through a variety of aspects of the visual analysis, approaching the ability of an expert. Some studies have been carried out using thermal images and machine learning in the early diagnosis of diseases using thermography. Among these, some important ones are [1] who used the support vector machine (SVM) classifier, and [4] who developed a methodology for identification, classified the images through the SVM classifier and optimized them by genetic algorithms.

In this context, the present study aimed to develop a software program, based on image processing and computer vision techniques, as an aid tool in the monitoring and early detection of clinical conditions of bovine mastitis.

\section{RELATED WORK}

The study was carried out in a milk production unit, Roçadinho Farm, located in the municipality of Capoeiras, Agreste Mesoregion, Vale do Ipojuca Microregion, Pernambuco, Brazil ( $8^{\circ} 36^{\prime} 33^{\prime \prime}$ South latitude, $36^{\circ} 37^{\prime} 30^{\prime \prime}$ West longitude and altitude of $733 \mathrm{~m}$ ).

The average rainfall of the region is $588 \mathrm{~mm}$ year-1, with an average annual temperature of $22.1{ }^{\circ} \mathrm{C}$. According to 
Köppen's climatic classification, the climate of the region is characterized as Bsh, semiarid [17].

The selection of animals consisted of Girolando cows of the same order of parturition, lactation stage, age, weight, body score, production and blood degree, which were monitored to obtain thermal images of the udder. The quantity of samples was determined according to the selection criteria and totaled 24 animals.

The clinical condition of the animals was established by the California Mastitis Test (CMT), before milking (after discarding the first streams of milk), because at this time milk fat content is low and does not interfere with the visual results of the CMT score. The test was performed for each mammary quarter, attributing scores that ranged from 0 to 5 : in score zero, no formation of precipitate (healthy); in score 1, slight precipitation (trace of infection); in score 2, moderate precipitation; in score 3 , clear precipitation without gel formation; in score 4, distinct gel formation; and in score 5, strong gel formation. In order to limit the subjectivity in the interpretation of the results, only cows with scores from 2 to 5 were considered in the selection of animals with subclinical mastitis.

To detect the cases of clinical mastitis, the black-bottomed mug test was performed. In this test it was possible to detect visible changes in milk (lower volume secreted, lumps, pus or watery appearance). In addition, sensitivity to touch in udder and teats was observed in the animals, due to the presence of the inflammatory condition.

Thermal images of the udder were obtained using an infrared thermographic camera, with resolution of $0.01{ }^{\circ} \mathrm{C}$, focal length of $1.0 \mathrm{~m}$ and emissivity adjusted to 0.98 , which is used according to the Quick Report application. The images were recorded in the morning, before the first milking of the animals, between $05 \mathrm{~h} 00$ and $07 \mathrm{~h} 00$, from the left anterolateral, right anterolateral, posterior and inferior views, four images per animal, totaling 96 thermal images for analyzing their respective mammary quarters (Figure 1).

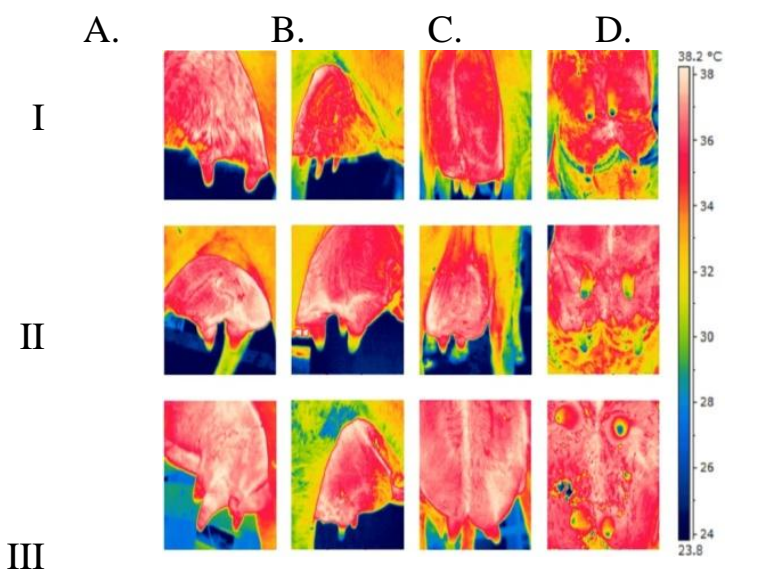
Figure 1. Thermal images referring to the clinical pictures
and perspectives used in the analysis

The thermal images were visually analyzed using the Flir QuickReport ${ }^{\circledR}$ program, with adjustment of the emissivity, ambient temperature and relative humidity values obtained at the time the images were recorded. Meteorological variables (ambient temperature and relative humidity) were recorded using a HOBO U12-12 Datalogger.

\subsection{Descriptive statistics}

First, the mammary quarters (anterior right, left, posterior left and right) were analyzed using descriptive statistics to observe the temperature variation between the rooms of the different clinical pictures (mean, median, standard deviation, coefficient of variation, kurtosis and normality) The criterion adopted to determine the coverage area of each mammary quarter was developed from a Cartesian plane measuring $2.4 \mathrm{x}$ $0.75 \mathrm{~mm} 2$, adopting a spacing of $5 \mathrm{~mm}$ for each pixel, referring to the surface temperature values for the composition in the selected area, disregarding the edges; thus, a $25 \times 80$ mm matrix was generated with 102 sampled points (Figure 2).

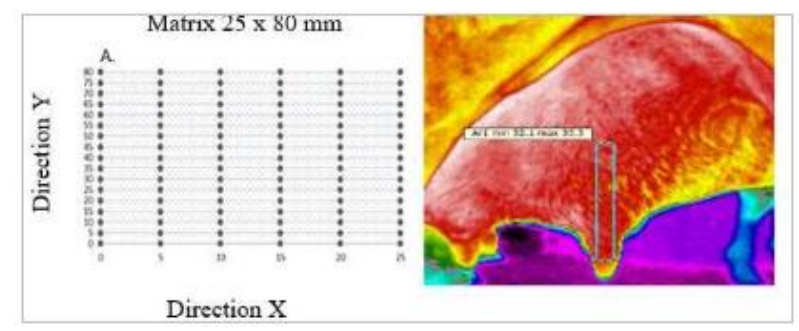

Figure 2. Sampling grid with $\mathrm{X}$ and $\mathrm{Y}$ coordinates with 102 points (A) referring to the surface temperature of the selected area (B) on the mammary quarter

\subsection{Image analysis}

After adjusting the images, all were converted to grayscale and the background was removed (pre-processing), then the images were segmented manually, following the thresholding method. The technique consists in decomposing a digital image into two groups of pixels, those which have a level of gray below the threshold and those which have a level of gray above the threshold [2] The division between these classes was carried out during processing, from a binary image, by grouping the points of the foreground (object) with value " 1 " and giving value " 0 " to the others, thus defined as background. The segmentation of the image facilitated the next step, which used only the region of interest (ROI), udder surface, based on the temperature range used in the procedure, between 34 and $38{ }^{\circ} \mathrm{C}$, for being the hottest region of the images.

The pre-processing step was performed with the ImageJ program, used for the processing and analysis of images, developed by Wayne Rasband at the National Institute of Mental Health, USA, in Java language. In the phase of extraction of characteristics, the algorithm developed scanned the ROIs, extracting essential information, that is, locating the clusters. Cluster labeling was carried out using the HoshenKopelman algorithm (Figure 2), which allowed labeling clusters in a predefined grid, where each cell can be labeled as either "occupied" or "unoccupied". The algorithm was developed to be applied in two-dimensional or threedimensional networks and is based on the detection of clusters connected in a network and on the labeling of the grid involved, so that all connected cells shared the same label [8] The algorithm scans the grid in question and, every time an occupied cell is encountered, it checks if that cell has neighboring cells that have already been scanned. Thus, first, an operation is performed to specify that these neighboring cells are in fact members of the same equivalence class. Then, the operation is performed to locate a representative member of this equivalence class with which the current cell will be labeled. On the other hand, if the current cell has no neighbors, it will receive a new label. 
The implementation of the algorithm was based on the principle of data organization, through the size of the clusters where there are two vectors, one indicating the size and midpoint of each cluster and the other indicating the data on individual points. The matrix $(\mathrm{x}, \mathrm{y})$ used to read/write colors on the screen was also considered.

According to the implemented function, first the clusters were organized by size. Following this step, the algorithm scanned all the clusters, giving them a green color and, after identifying the largest cluster, it highlighted this cluster in blue. The color representation scale used was from 0 to 255 , adopted because of the convenience of storing each color value in 1 byte ( 8 bits): green - RGB $(0 ; 255 ; 0)$ and blue RGB (0;0;255).

The results obtained by the classifier algorithm were evaluated using the measures of accuracy, sensitivity and specificity. Accuracy determines the percentage of correctly classified images (considering all classes), Eq. (1). Sensitivity allows the calculation of the percentage of cases of mastitis correctly classified as positive, Eq. (2). Specificity determines the percentage of normal cases (without mastitis) correctly classified as healthy, Eq. (3). All mathematical expressions were extracted from [4].

\section{RESULTS AND DISCUSSION}

When checking the values of the descriptive statistics of the mammary quarters, differences were observed between the clinical pictures.

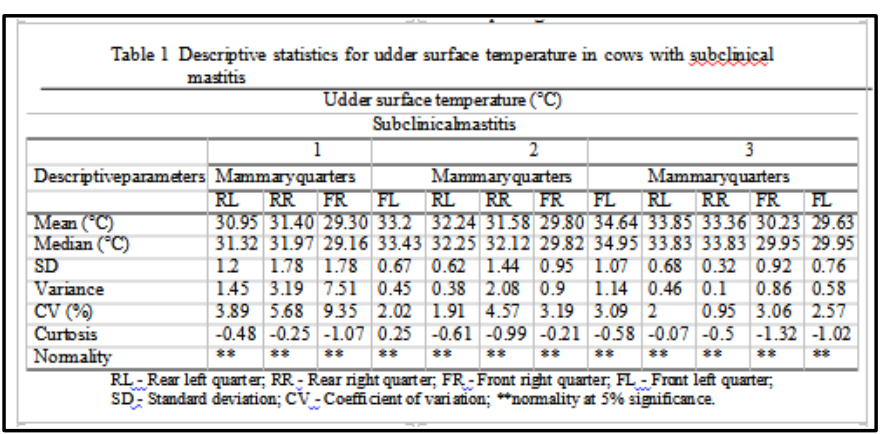

The average temperatures on the surface of the mammary quarters with subclinical mastitis (score 5) were: $34.64^{\circ} \mathrm{C}$ \pm 0.67 (front left side), $33.85^{\circ} \mathrm{C} \pm 0.68$ (rear left side) and $33.36^{\circ} \mathrm{C} \pm 0.32$ (rearight side), respectively (Table 1 ). Negative mammary quarters presented temperatures ranging from $29.3^{\circ} \mathrm{C} \pm 1.78$ to $31.58^{\circ} \mathrm{C} \pm 0.62$ (Table 2). According to Polat et al. (2010), quarters with sub- clinical mastitis presented a surface temperature $2.35{ }^{\circ} \mathrm{C}$ higher than that of healthy quarters. However, the values found were $35.80^{\circ} \mathrm{C}$ for quarters with mastitis, and $33.45^{\circ} \mathrm{C}$ for healthy quarters, diverging from the values found in this study -5.3 to $4.55^{\circ} \mathrm{C}$ above the surface temperature of healthy udders. [5] reported temperatures lower than those found by [13] for subclinical mastitis. Udder temperature variation magnitude is associated with infection stage and room temperature during thermal image capturing.

With respect to the analyzed images, there was a higher occurrence of animals with mastitis on the front left quarter (FL); the temperature of these quarters presented a higher mean, smaller variation, with the coefficient of variation $(\mathrm{CV}$, $\%$ ) indicating low variability and smaller standard deviation values, followed by the rear left quarter (RL),

he front right quarter (FR), and the rear right quarter (RR). According to [18] a CV < 15\% indicates low variability.

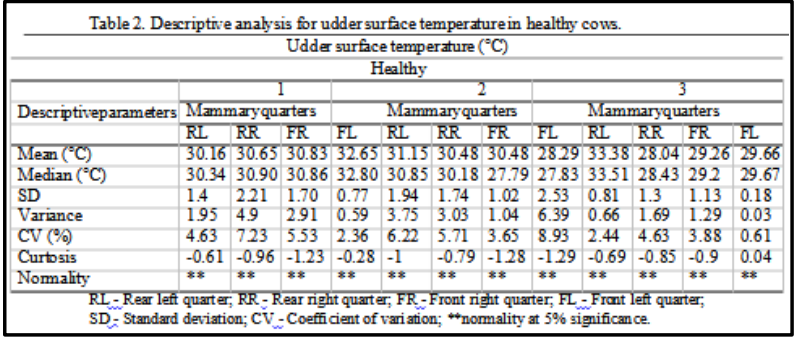

The animals classified with clinical mastitis had an average udder surface temperature of $37.58 \pm 0.33 \mathrm{oC}$ to $37.11 \pm 0.61^{\circ} \mathrm{C}$ (Table 3). Mammary quarters with clinical mastitis presented higher temperatures when compared to those quarters with subclinical mastitis and healthy ones (Tables 1 and 2). Values for coefficients of variation indicated low variability (Warrick $\&$ Nielsen, 1998), and so did the standard deviations. Kurtosis values were negative, indicating a less steep normal distribution curve. This allows inferring that the evolution of the infectious case raises the udder surface temperature with a reduction in data spatial variability.

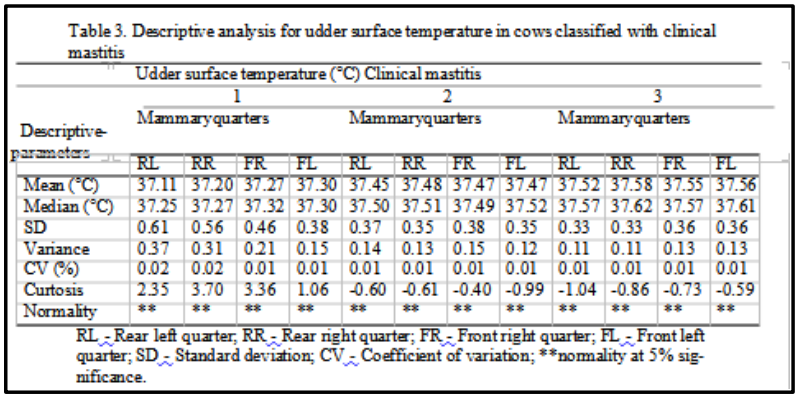

The images were processed on a white background defined by the udder surface. The ImageJ's Clear Outside tool was used to define the region of interest, guaranteeing the best view of the udder of the animals before analysis. This tool helped in subtracting objects of "no interest", such as the environment and legs of the animal.

The samples of thermal images used for detecting the clinical conditions of the animals were subjected to the processing through segmentation (thresholding) to extract characteristics of interest, located in the central region of the image (udder) base on the temperature range between 34 and $38{ }^{\circ} \mathrm{C}$, referring to the region of highest temperature in the images.

Studies such as those of [3] and [11] confirm the efficiency of the thresholding method for the use of thermal images, with emphasis on early diagnosis of cancer and somatic cell count in bovine milk through images obtained directly from the optical microscope.

The results were presented in such a way to allow udder surface temperatures of the animals to be evaluated and compared through the images, classified by the unsupervised method, based on the Hoshen-Kopelman algorithm for cluster identification.

The classification was performed pixel by pixel, using only the spectral similarity of each pixel to locate homogeneous regions, identified by gray levels in the images. Thus, the result of the classification was a digital image consisting of pixels represented by colors.

Figure 2 shows the segmented thermal image of $600 \times 600$ pixels (360,000 pixels) and the one-dimensional result of its classification. The digital classification was identified by means of spectral classes (areas with similar spectral characteristics). The image consisted of a map of pixels, 
represented by the blue and yellow colors, i.e., the digital classification process transformed a large number of gray levels in each spectral band, which in this case were two concatenated bands, into a number of classes that varied according to the research goal, which was to classify the animals according to the clinical conditions (healthy, with clinical mastitis and with subclinical mastitis).

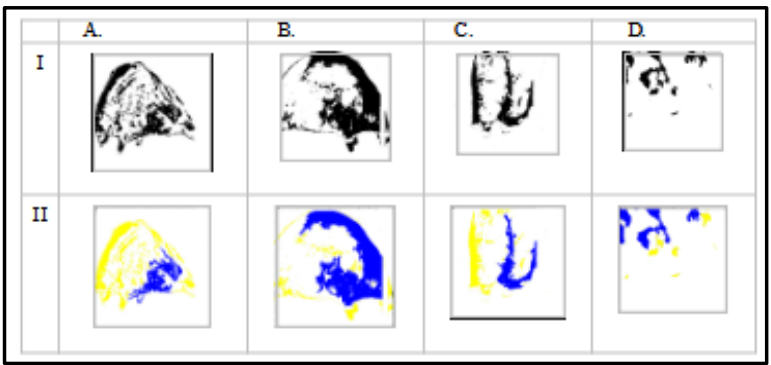

Figure 2. Segmented (I) and classified (II) thermal images of healthy animals taken from the right anterolateral (A), left anterolateral (B), posterior (C) and inferior (D) views

The class indicated by the blue color, referring to the largest cluster (more homogeneous region of the image) had averages of $69,789,86,811,55,565$ and 35,660 pixels for the images of the healthy animals taken from the left anterolateral (Figure 2A-II), right anterolateral (Figure 2B-II), posterior (Figure $2 \mathrm{C}$-II) and inferior (Figure 2D-II) views, respectively.

The largest clusters of the images for healthy animals corresponded to $19.38,24.11,15.43$ and $9.9 \%$ of the total pixels of the images taken from the left anterolateral, right anterolateral, posterior and inferior views, respectively (Figure $2 \mathrm{~A}, \mathrm{~B}, \mathrm{C}, \mathrm{D}-\mathrm{II})$.

For the images of animals classified with subclinical mastitis, the values of clusters for the temperature range established in the respective views were 165,090 (Figure 3A-II), 140,137 (Figure 3B-II), 210,931 (Figure 3C-II) and 217,522 (Figure 3D-II). The clusters for animals with subclinical mastitis comprised 38.93, 45.86, 58.59 and $60.42 \%$ of the total (360,000 pixels), respectively (Figure $3 \mathrm{~A}, \mathrm{~B}, \mathrm{C}, \mathrm{D}-\mathrm{II}$ ).

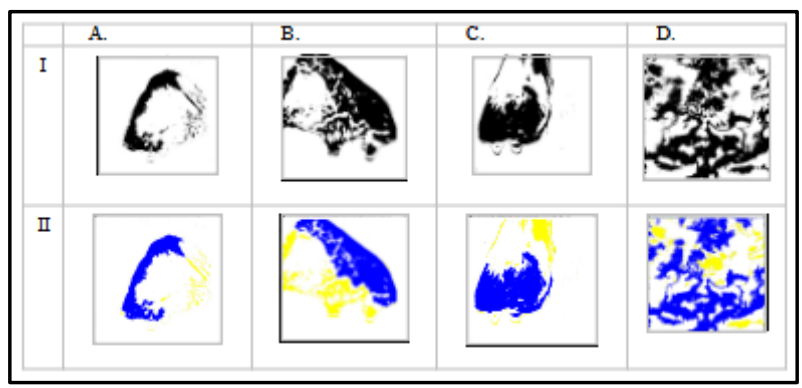

Figure 3. Segmented (I) and classified (II) thermal images of the animals with subclinical mastitis taken from the right anterolateral (A), left anterolateral (B), posterior (C) and inferior (D) views

According to [13] surface temperature in quarters with subclinical mastitis was $2.35{ }^{\circ} \mathrm{C}$ higher than that

of healthy quarters. [5] found lower temperatures than those reported by Polat (2010) for subclinical mastitis.

The images of the animals with clinical mastitis showed averages of 251,022 (Figure 4A-II), 284,928 (Figure 4B-II), 305,148 (Figure 4C-II)) and 281,025 (Figure 4D-II)) clusters within the udder surface temperature range, in the left anterolateral, right anterolateral, posterior and inferior views, respectively. The percentage representation of the clusters was $79.15,69.73,84.76$ and $78.06 \%$, respectively (Figure 4 A, B, C, D - II).

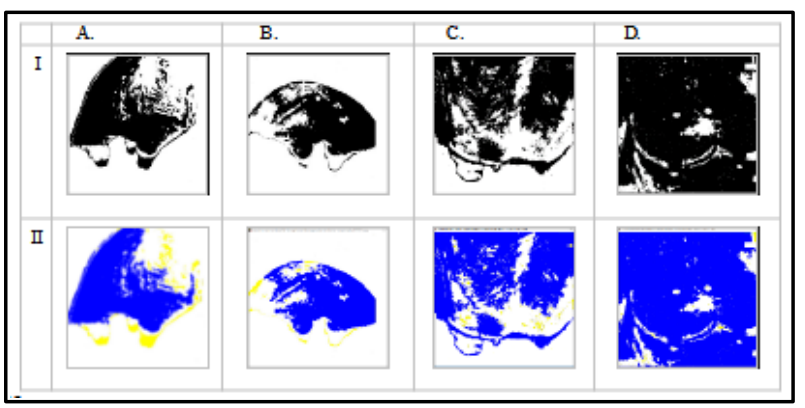

Figure 4. Segmented (I) and classified (II) thermal images of the animals with clinical mastitis taken from the right anterolateral (A), left anterolateral (B), posterior (C) and inferior (D) views

The thermal images of the udder of the animals, in their respective clinical conditions, were classified by the visual analysis software program, which showed accuracy of $90.9 \%$, specificity of $57.14 \%$ and sensitivity of $85.71 \%$, according to the Hoshen-Kopelman algorithm. It was observed that the thermal images followed a morphological pattern, which allowed the evolutionary profile of mastitis to be determined. Similar results were found by [4], who classified images through SVM and optimized them by genetic algorithms and obtained accuracy, specificity and sensitivity of 79.92 and $88 \%$, respectively, in the classification of their images. [1] using the support vector machine (SVM) classifier, found accuracy of $88.10 \%$, sensitivity of $85.71 \%$ and specificity of $90.48 \%$.

The thermal images of the udder of the animals with mastitis were more homogeneous, i.e., they had higher occurrence of temperatures within the range from 34 to $38^{\circ} \mathrm{C}$, established in the pre-processing. Animals classified with subclinical mastitis showed an intermediate condition, and animals classified as healthy had lower occurrence of these temperatures.

A factor that interfered in the classification process, but was not decisive, was that the images did not follow the same angle of capture when the method was applied. This was caused by the arrangement of the animals in the milking room and by the thermal imager, which was not fixed, but rather a handheld device, so it depended on the operator position.

\section{CONCLUSIONS}

The computer program was able to classify thermal images of the udder surface, associated with clinical conditions of bovine mastitis, contributing to the early detection of the disease.

The angle at which the images were recorded can influence the result of the image classification, because of the subtraction of some pixels from the region of interest.

\section{REFERENCES}

[1] Acharya, U. R, Ng, E.Y.; Tan, J.H. and Sree, S.V. (2012) Thermography based breast cancer detection using texture features and support vector machine. Journal of medical systems, Springer, v. 36, n. 3, p. 1503-1510, 2012 
[2] Azevedo, E. and Conci, A. (2003). Computação gráfica: teoria e prática. Computação gráfica: teoria e prática. Rio de. Janeiro: Elsevier, 353p

[3] Baffa, M.F.O., Cheloni, D.J.M., Lattari, L.G. and Coelho, M.A.N. (2016). Segmentação Automática de Mamas em Imagens infravermelhas utilizando limiarização com refinamento adaptativo em bases multivariadas. Revista de Informática Aplicada, 12(2).

[4] Borchartt, T. B., Conci, A., Lima, R.C.F., Resmini, R and Sanchez, A. (2015). Breast thermography from an image processing viewpoint: A survey. Signal Processing, Elsevier, 93(10), 2785-2803

[5] Bortolami, A., Fiore, E; Gianesella, M., Corro, M., Catania, S. And Morgante, M. (2015). Evaluation of the udder health status in subclinical mastitis affected dairy cows through bacteriological culture, somatic cell count and thermographic imaging. Polish Journal of Veterinary Sciences, 18( 4), 799-805,.

[6] Digiovani, D.B., Borges, M.H.F.,Galdioli, V.H.G., Matias, B.F., Bernardo, G.M.,Silva, T.R.; Fávaro, P.C.; Júnior, F.A.B.,Lopes, F.G.; Júnior, C.K. and Ribeiro, E.L.A. (2016) Infrared thermography as diagnostic tool for bovine subclinical mastitis detection. Revista Brasileira de Higiene e Sanidade animal,10(4), 685-692.

[7] Gloster, J., Ebert, K., Gubbins, S.,Bashiruddin, J. and Paton, D.J. (2011) Normal variation in thermal radiated temperature in cattle: implications for foot-and-mouth disease detection. BMC Veterinary Research, 7, 17466148 .

[8] Hoshen, J. and Kopelmann, R. (1976). Percolation and cluster distribution. I. Cluster multiple labeling technique and critical concentration algorithm. Physical Review B. Volume 14, Number 8,1976

[9] IBGE, Instituto Brasileiro de Geografia e Estatística. Censo Agropecuário 2017. Available at: https://biblioteca.ibge.gov.br/visualizacao/periodicos/309 3/agro_2017_resultados_preliminares.pdf Accessed on Nov 6, 2017.
[10] Langoni, H., Salina, A., Oliveira, G.C., Junqueira, N.B., Menozzi, B.D. and Joaquim, S.F. (2017). Considerações sobre o tratamento das mastites. Pesquisa Veterinária Brasileira ,37(11), 1261-1269.

[11] Melo, G.J.A., Neto, B.A.M., Gomes, V., Almeida, L.A.L. and Lima, A.C.C. (2014). Método de limiarização automática para a contagem de células somáticas em imagens microscópicas. Revista GEINTEC.4(3),1283 1291.

[12] Pezeshki, A., Stordeur, P., Wallemacq, H., Schynts, F., Stevens, M., Boutet, P., Peelman, L.J., Spiegeleer, B., Duchateau, L., Bureau, F. And Burvenich, C. (2011) Variation of inflammatory dynamics and mediators in primiparous cows after intramammary challenge with Escherichia coli. Veterinary Research, 42(15).

[13] Polat, B.,Colak, A.,Cengiz, M.,Yanmaz, L.E.,Oral, H., Bastan, A.,Kaya, S. and Hayrli, A. (2010). Sensitivity and specificity of infrared thermography in detection of subclinical mastitis in dairy cows. Journal Dairy Science. Source: Journal of dairy science. 93(8), 3525-3532.

[14] Rasband, W. ImageJ documentation. Available at: < https://imagej.nih.gov/ij/docs/index.html > Accessed on March 25, 2019.

[15] Redaelli, V.,Bergero, D.,Zucca, E., Ferrucci, F.,Nanni, L.,Crosta and L.,Luzi, F. (2013) Use of Thermography Techniques in Equines: Principles and Applications. Journal of Equine Veterinary Science, 1-6.

[16] Sá, J.P.N., Figueiredo, C.H.A., Neto, O.L.S., Roberto, S.B.A., Gadelha, H.S. and Alencar, M.C.B.. (2018). Revista Brasileira de Gestão Ambiental, 12(1),01- 13, 2018.

[17] Vianello, R. L. And Alves, A. R. (1991). Meteorologia básica e aplicações. Viçosa: UFV - Imprensa Universitária. $449 \mathrm{p}$.

[18] Warrick, A.W. and Nielsen, D.R. (1998). Spatial variability of soil physic properties in the field. New York: Academic, 655-675. 